\title{
The Analysis of the Development Situation and Trend of the City-Oriented Cold Chain Logistics System for Fresh Agricultural Products
}

\author{
Xingang Weng, Jiuyi An, Hui Yang \\ Beijing Wuzi University, Beijing, China \\ Email: anjiuyi@126.com
}

Received 8 October 2015; accepted 9 November 2015; published 12 November 2015

Copyright (C) 2015 by authors and Scientific Research Publishing Inc.

This work is licensed under the Creative Commons Attribution International License (CC BY). http://creativecommons.org/licenses/by/4.0/

\section{(c) (i) Open Access}

\begin{abstract}
The city acts as political, culture, and economic center, with fast development of chain business, e-commerce, and other modern trade industries and urban advance of rural integration's process, the consumption scale and category of fresh agricultural constantly grow, and it must raise urgent needs of city cold chain logistics, while also cause huge of traffic pressure, which makes contradictions between external uneconomic nature of city distribution and the sustainability of city economic development more explicit. Fresh agricultural products are necessities to urban residents, and it is basic guarantee of urban life stability to build a perfect cold chain logistics system for fresh agricultural products, it is also basic conditions supporting the development of the city. This article studies on cold chain logistics system for fresh agricultural products and analyzes the situation of the city-oriented cold chain logistics system for fresh agricultural products, and its development trend.
\end{abstract}

\section{Keywords}

City-Oriented, Fresh Agricultural Products, Cold Chain Logistics System, Development Trend

\section{Introduction}

The increasing demand for the fresh agricultural products makes cold chain logistics of fresh agricultural products meet the requirements of individual needs of agricultural products both in the technical and operational requirements, which results in high cost of agricultural product logistics operations. And fresh agricultural prod- 
ucts are necessities to urban residents, and it is basic guarantee of urban life stability to build a perfect cold chain logistics system for fresh agricultural products, it is also basic conditions supporting the development of the city. The novelty of this article is analyzing production processing enterprises' cold chain service system, wholesale market cold chain service system, supermarkets-oriented cold chain distribution service system, cateringoriented enterprise cold chain distribution service system, cold chain house distribution service system, cold chain mainline transport services system and commodity reserves cold chain system from the perspective of cold chain logistics service system of agricultural products, and analyze its development trend. Urban development needs large scale of fresh agricultural products supply, supported by more competitive and advanced cold chain logistics system.

\section{The Analysis of Demand Characteristics and Development Situation of the City-Oriented Cold Chain Logistics for Fresh Agricultural Products}

With the improvement of the living standard of urban residents, people's personalized requirements on fresh agricultural products' diversity, freshness, timeliness of delivery get higher and higher. But property of high water content, short shelf life and perishable makes cold chain logistics of fresh agricultural products need diversification, high technical, complex operations management, higher operating costs and so on.

\subsection{The Analysis of Demand Characteristics of City-Oriented Cold Chain Logistics}

\subsubsection{The Diversification of Demand}

As living standards improve, idea and behavior in food consumption of residents are in significant changes. They have greater emphasis on fresh, security, convenience, and nutrition of food consumption, resulting in the diversification of the cold chain logistics' needs. One is the diversification of service demand. The property of extending the shelf life of the product of cold chain converts to maintain freshness and improve the quality of their products. Cold chains are mainly used for production, processing and storage of frozen and refrigerated food, and it is a means of ensuring product quality; they are also used for strategic reserves and commercial reserves of countries of poultry and vegetable food to extend the shelf life of products and sales. With the change of consumers' quality awareness and improvement, residents not only require the rich variety of products, timely delivery, and also on the quality, safety and freshness of fresh products, so tracking, processing, packaging, and other value-added services of fresh cold chain quality and safety are derived from two basic services around the cold storage and transportation. Another one is the diversification of service demand. Fresh agricultural products' distribution channels grow to be diversity with increasing demand scale for fresh agricultural products. Fresh e-commerce business, community chains, supermarkets and other channels led to the evolution of the cold chain of urban service mode.

\subsubsection{High Requirements of Security}

The cold chain of fresh agricultural products is attached to one end of the city living of urban residents, so quality and safety of agricultural products is more related to the health of consumers, or even threatens life. City management sector should increase supervision of the quality and safety of fresh agricultural products. Cold chain logistics as an important part of the city-oriented circulation of agricultural products, and is also the focus of regulators. The promotion of Beijing food assurance project and the operation of temperature control and traceable system realize the cold chain of the meat from production to sale, and improve the security of the cold chain, which increase service demands of cold chain logistics' monitor process [1]. Traceable system of food cold chain is not for a single node monitoring, but for the whole process of the product from production to transportation, sales, and finally into the hands of consumers.

\subsubsection{Cold Chain Logistics' Infrastructure Is Relatively Sound}

Infrastructure construction includes functional sites needing in completion of organization and management of cold chain logistics for fresh agricultural products, such as cold storage, fresh food distribution centers, storage facilities and transport equipment and terminal facilities. City as a market has more developed economies and comparatively strong demand, government enterprises for cold chain logistics infrastructure is higher than the national average. In Beijing, for example, the city's total of large-scale wholesale markets for agricultural products is more than 50 until 2012, nearly 800,000 tons of cold storage, refrigerated trucks are more than 3000, 
which provide protection for cold chain logistics of agricultural products.

\subsubsection{The Strong Constraints of System}

City's accelerated expansion and population overall tension agglomerate urban traffic resources, adding to traffic jams of the city; the other is the period of rapid growth of motorization in China, a geometric increase in vehicle ownership, further exacerbating the shortage of urban traffic, which causes serious congestion of city traffic and traffic environment continue to deteriorate. Under the situation of growing tensions in urban traffic resources and traffic demand continues to expand, ensure the movement of people and limit the movement of freight vehicles are reluctant choose of urban managers. For fresh agricultural products, cars, trucks, dock and other problems widely reflected in the cold chain distribution are concentrated system of institutional constraints [2].

\subsubsection{The Prominence of Social Nature}

Cities' cold-chain delivery for fresh agricultural products is not just a "store" or "distribution" issue. Cities' cold-chain delivery for fresh agricultural products as one of the city livelihood project- "vegetable basket" projects' an important part, and it focuses more on the operational goals of the city, not just the enterprises' target. It requires the overall harmony of the city, rather than the just process's efficiency. In essence, cities' cold-chain delivery is in the condition of government's involvement in the management, forming a tripartite (supply and demand side and the Government side) linkage mechanism completed by the market. City's delivery market is under the conditions of many management objectives of the city, and the Government system has played an important role in this market [3].

\subsection{The Analysis of City-Oriented Cold Chain Logistics' Present Development Situation}

\subsubsection{City-Oriented Cold Chain Logistics' First Prototype}

Enterprises like Sinotrans and Ann have strengthened strategy cooperation and resources integration with enterprises upstream and downstream, and expand cold chain logistics business actively around city market; meat processing enterprises like Shuanghui, Yurun, and Zhongpin are speed up in logistics business and assets restructuring, organizing cold chain logistics companies in independent accounting, to perfect cold chain network, gradually transfer to mature third-party cold chain logistics enterprises, becoming main force of cold chain industry; large chain commercial enterprise perfect cold chain management in terminal sales link and speed up health fresh food distribution's development, they develop the third-party cold chain logistics center providing public services based on the internal distribution In the progressive development of enterprises. Cold chain logistics enterprises show a trend of networking, standardization, scale, and group development.

With social and enterprises' enhanced awareness on cold chain logistics, their requirements on cold chain logistics service quality requirements become increasingly high. Cold chain industry competition pressure constantly strengthen, they keep their competition advantages through constantly innovation of logistics service mode, integration of resources, and full upgrade of their service's quality and level. The mode of cold chain service transfer single warehouse and transportation to cross- and across regional integration service, professional cold chain service is in steady development.

\subsubsection{Rapid Growth of Scale of Urban Cold Chain Logistics}

Increased demand of urban residents' average consumption for fresh products, working together with the expanding urban population size, which make cold chain logistics demand continue to increase.

With the improvement of consumption, Beijing residents pay attention to not only the satisfaction of amount but also quality, and quality and structure of consumption has undergone significant changes, in particular the proportion of the fresh food in food consumption structure of rural residents is significant increased. The increasing demand for vegetables, poultry, aquatic products, fruits and dairy products must promote the development of food cold chain logistics industry.

\subsubsection{The Progress in the Joint Distribution of the City Cold Chain}

Beijing as the mega-cities, its high level of diversification of trade circulation industry and residents' consumption offer great potential to city cold chain. Perfect node facility and distribution network of cold chain logistics, 
making rapid development of cold chain logistics and cold chain distribution capacity can be improved. The logistics industry is an industry that there are significant economies of scale. Only through integration of resources and high intensive, the cost of business and society can be reduced. Joint distribution is the first choice for highly intensive and highest stage of cold chain logistics development of the city.

From a micro perspective, achieving a multi-temperature of cold chain logistics-distribution can improve efficiency of cold chain logistics operation, reduce operating costs, save a lot of money, equipment, land, human resources, and so on. Companies can focus on core business, promote the growth and proliferation of enterprises, expand market's reach, eliminate closed sales network, and build coexistence and shared environments.

From the standpoint of society as a whole, achieving a multi-temperature of cold chain logistics-distribution can reduce overall social refrigerated trucks, reduce the phenomenon of prejudice in urban transportation due to discharge, improve transport conditions; through centralized treatment of cold chain logistics, to improve the loading rate of cold-chain vehicles and save space on the cold chain logistics and human resources, improve cold chain logistics business environment and improve the quality of social life as a whole.

\subsubsection{The Network of the Cold Chain Logistics Operation}

The feature of regional, remote marketing, anti-season of fresh products supply, putting forward higher requirements to the cold chain logistics services and efficiencies, particularly the main-line transportation of transregional of the cold chain and the network of city cold chain distribution services. Cold chain logistics regional network operation system has gradually mature, one is achieving integration of cold chain logistics system of across regional and national long-distance transportation for high value features fruits and vegetables under full cold chain; another is achieving regional cold chain logistics system of apples, incense pears, tropical fruit, and other fruit can be region refrigerated, and transported to sales in plan; the third is achieving network cold chain logistics system of transportation from south to north and east to west of garlic moss, asparagus, and other anti-season vegetables and special vegetables.

In Beijing, for example, local production of melon, aquatic products, meat, poultry, and other fresh food products is far from meeting the consumption demand of the residents. Vegetable production is greater than the demand, but on the structure and season, need outsourcing vegetables to be added. According to the Beijing Municipal Bureau of agriculture information center's survey in the main wholesale market, it shows that Beijing's vegetables, fruit, meat and other food products rely mainly on Shandong, Guangdong, Hainan, Hebei, Shanxi, Inner Mongolia and other places' supply. After years of development, supported by Beijing as the core of main production and sale of agricultural products, we have built a more perfect cold chain logistics network system for fresh agricultural products, effectively protect agricultural products' demand in Beijing.

\subsubsection{The Diversification of Cold Chain Logistics' Operation Mode}

The operation mode of cold chain logistics for fresh agricultural products is shown in Figure 1. Fresh agricultural products through wholesale and retail enterprises to reach consumers after output by production enterprises, and cold chain logistics business or fresh products processing enterprises may participate in all links. Different fresh agricultural products circulation patterns determine the cold chain link number, and development level of different subject-driven circulation pattern differs, so we need to depend on the product quality orientation to decide whether to take measure of the cold chain.

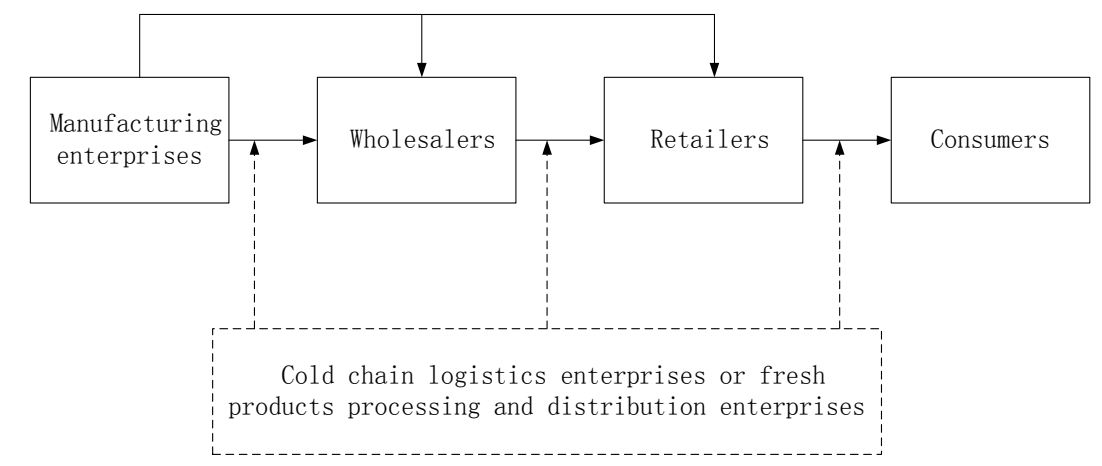

Figure 1. Diagram of fresh agricultural products' circulation pattern. 
Cold chain in wholesale link main play roles through distribution cold storage's construction in wholesale market, providing service for temporary products storage of stationed businesses; in retail link mainly act by refrigerated container and supermarket health fresh distribution center to guarantee products quality and quality and reduce loss; in circulation processing link, vegetables, fruit, processing distribution center play main role; in city end distribution link, mainly through cold chain logistics city distribution enterprises' refrigerated store and refrigerated distribution. The cold chain is essential mean for enterprises to achieve professional service.

The operation mode of fresh agricultural cold chain logistics generally can be divided into following four classes: one is oriented by agricultural and sideline products' wholesale market; another is oriented by large chain supermarket; the third is oriented by processing and distribution enterprises; the forth is oriented by third-party cold chain logistics enterprises. At present, the mode dominated by agricultural products wholesale market share large proportion, and this model still dominates in some time of the future [4]. But with the development of agricultural industrialization and national support for farm-supermarket chain, the mode dominated by large supermarkets will continue to increase its share.

\subsubsection{The Equipment of Cold Chain Turned to Be Energy-Efficient}

Food cold chain logistics involves raw material purchasing, processing, transportation and storage until sale and many other areas. Currently, all sectors have formed a complete technical system, in order to ensure the cold chain logistics development. The green farming, cultivation technology and harmful material detection technology in procurement link can guarantee cold chain logistics quality from origin; GPS, GIS, EDI, barcode, MIS, and temperature humidity infrared remote sensing technology can achieve full control; vacuum pre-cold technology, ice temperature pre-cold technology in origin processing link can improve products quality and extend preservation period; automation cold storage, gas adjustable library, multi-temperature cold storage and other technologies in storage link can effectively extend store preservation period; refrigerated container, "three paragraph type" refrigerated transport vehicles and other technologies in transport link can provide "door to door" service.

At present, the cold chain treatment technology adapted to the situation of low energy consumption, low cost in Beijing is expanded. Fresh-food processing and distribution businesses, leading manufacturers, professional cold chain logistics business and wholesale markets and supermarket chains, increase investment on cold storage facilities of more advanced, energy-saving, environment friendly, efficient application based on technology and full use of existing cold storage facilities. In addition, all kinds of new conductive materials and cold chain logistics technology research results are effectively transformed, and economic cooling installations, mobile cooling unit, cold chain transport of energy saving and environmental protection, advanced display sales of containers and cold chain facilities continued to emerge.

\section{The Analysis of Cold Chain Logistics Service System for Fresh Agricultural Products}

Cold chain logistics service system for fresh agricultural products is a complex system involving agricultural production, wholesale, retail, logistics service, and multiple subjects and links. City-oriented cold chain logistics service system for fresh agricultural products includes route refrigerated transport, city cold chain distribution and refrigerated storage, circulation processing and sales and other links, currently has formed production processing enterprise cold chain service system, wholesale market cold chain service system, supermarketsoriented cold chain distribution service system, catering-oriented enterprise cold chain distribution service system, cold chain house distribution service system, cold chain mainline transport services system and commodity reserves cold chain system (as shown in Figure 2).

\subsection{Wholesale Market Cold Chain Service System}

Wholesale market cold chain service system refers a integrated cold chain service system that fresh food wholesale market establish supply chain production base of fresh food, dealer, professional cooperatives, retailers, build cold storage itself and purchase refrigerated transport tool or integrate cold storage and refrigerated transport tool possessed by upstream and downstream enterprises, in order to ensure fresh food in low temperature state in store, transport distribution, wholesale. Wholesale market cold chain service system is important part of society fresh food cold chain logistics systems. Cold chain service in the wholesale market is of great 


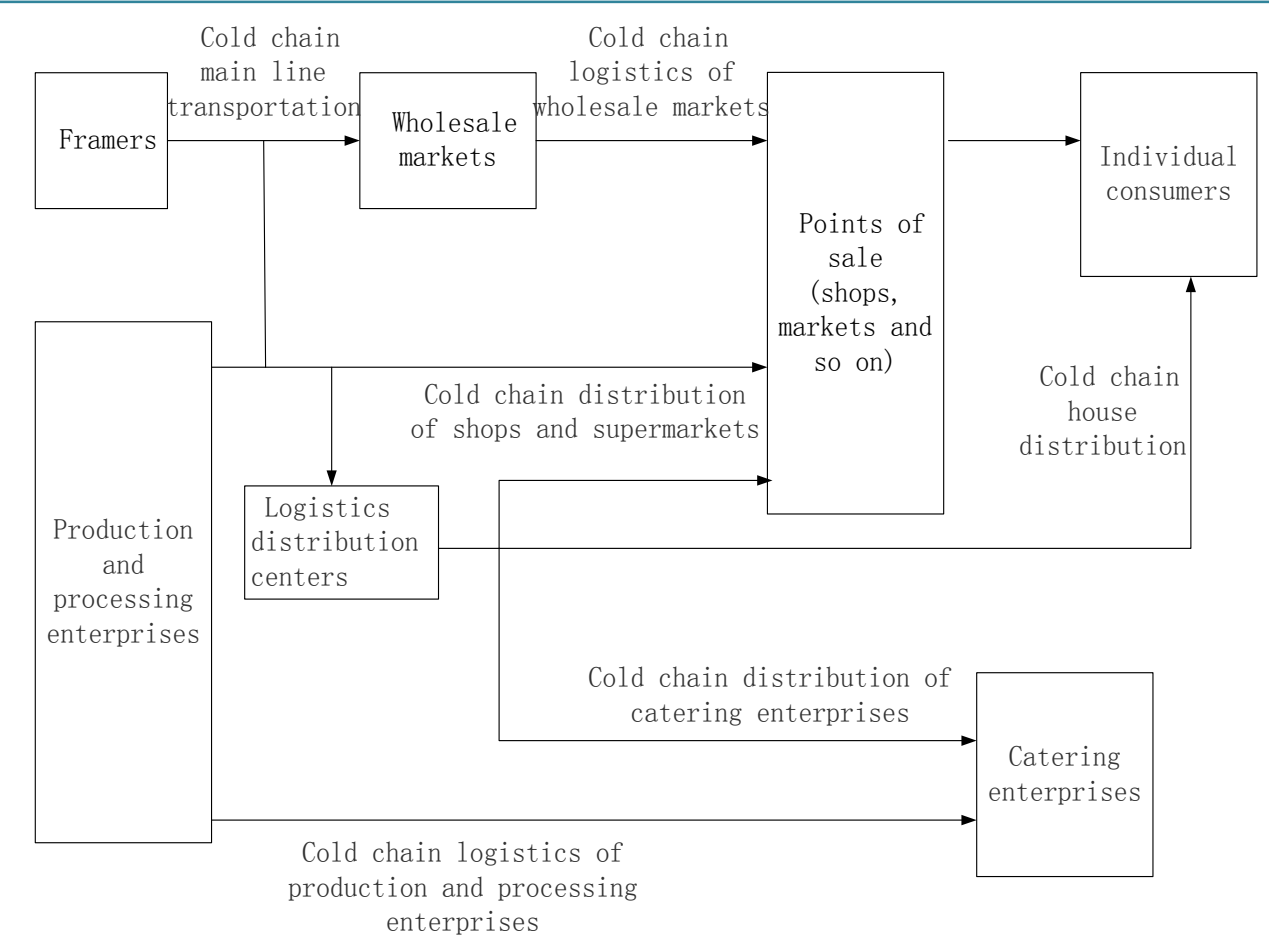

Figure 2. Service system of cold chain logistics for fresh agricultural products.

significance to perfect the food cold chain logistics system and the upgrading of the wholesale market. Main mode of wholesale market cold chain service includes several modes as following: one is cold storage service, and it is main content in wholesale market; another is temperature control construction in trading places, and currently this cold chain service in wholesale market within appeared broken chain; the third is refrigerated transport vehicles configuration, and it is main direction of future wholesale market cold chain service, that is freight vehicles (containing delivery, procurement and market within distribution vehicles) of fresh agricultural products are required to configure refrigerated vehicles according to need of shipped products, such as provisions for pork refrigerated transport vehicles in wholesale market.

At present, the cold chain plays a role in the wholesale market mainly through the construction of cold storage to serve businesses' temporary storage. Cold storage has an important role in preservation of fresh food, especially in cold storage of agricultural products wholesale market, which is the source of cold chain circulation of agricultural products. Currently due to high land price, high cold storage operations cost and other factors, wholesalers tend to build cold storage in the production place, and plan to small batch transportation of products according to the market situation, so they do not depend on the cold storage in a wholesale market so much. Cold storage of agricultural products of wholesale market in urban central area is mainly used for storing small amounts of working capital goods or the rest of goods expect selling.

\subsection{Production and Processing Enterprises Cold Chain Service System}

Raw and fresh food processing industry is the core of development of agricultural industrialization, is the key to extend the agricultural industrial chain. With the development of processing industry of agricultural products, fresh food production and processing enterprises gradually gather from the messy to park, change from cottage to modern enterprise, their products change from low common quality to high brand quality. Fresh food processing enterprises use their resources, firstly build or jointly construct community stores and control sales terminal, then construct health fresh food logistics center or distribution center, further to extend to raw materials suppliers. This self-run cold chain logistics- "integration of supply and sale" is to make enterprise be big and strong, and gradually from a supply chain of regarding the processing as core node, from raw materials production supply, products processing, logistics, sales and eventually to consumers, as Figure 3 (the operation flowchart of production processing enterprise's cold chain logistics service). 


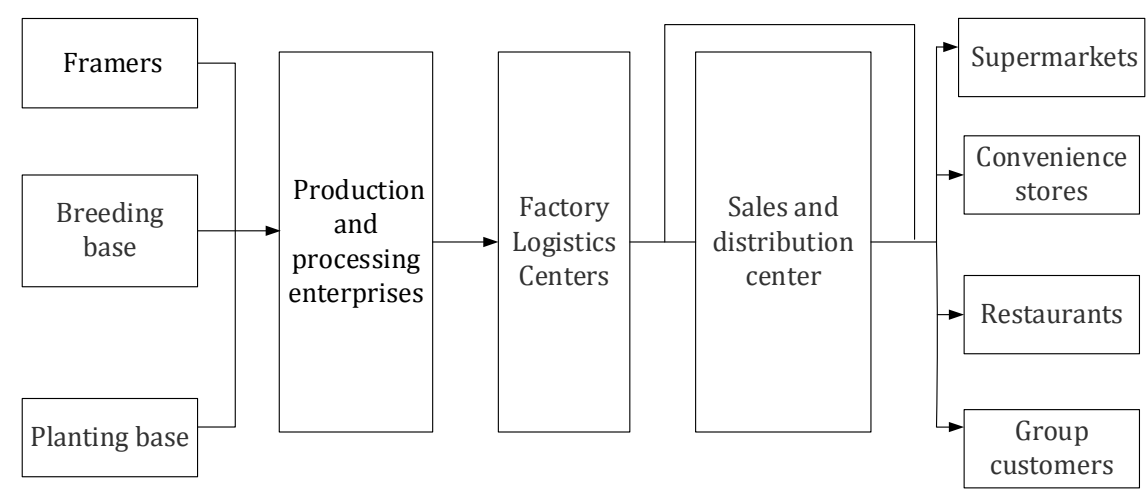

Figure 3. Flow chart of processing enterprises on cold chain logistics' service.

The cold chain logistics service of fresh food production and processing enterprises, due to the whole process logistics' less links, is convenient for the whole control and safety tracking of cold chain logistics, and enable effective communication in every link of the cold chain and information integration, so information could be delivered in a timely manner and be able to respond quickly to market changes, which helps add value of fresh food. But the scope of cold chain logistics service mode- "production integration" is narrow, cold fresh foods are prone to deterioration, causing the distribution's radiation radius of this mode especially the radius is relatively small.

\subsection{Supermarkets-Oriented Cold Chain Distribution Service System}

Enacted in December 2006, "the supermarket food safety practices" (for trial implementation) by The Ministry of Commerce, large supermarkets should ensure that every link in the chain as a whole refrigerated or frozen for food need to be refrigerated or frozen, such as meats, cooked meat, soy products, dairy products and frozen foods food. The refrigerated temperature needs to be $0^{\circ} \mathrm{C}-4^{\circ} \mathrm{C}$, and the freezing temperature must be less than-18 degrees. When they are sale at the Mall, each food storage counter must have dedicated person to control, and measure temperature and record regularly, in order to ensure food preservation conditions to meet the food safety standards. As for as the cold chain logistics of supermarkets, there are import-distribution model, manufacturer or supplier direct distribution model, third party logistics distribution mode and common distribution mode.

\subsection{Catering-Oriented Enterprise Cold Chain Distribution Service System}

Chain catering industry momentum, from fast food to the pot and then to the restaurant, restaurant chain has become the main business model in Beijing. In order to guarantee product quality and service quality and reduce wastage, catering-oriented enterprise cold chain distribution service system comes into being, and the cold chain plays as central kitchen's mode in restaurants chain. Catering-oriented cold chain distribution center originated "fast food", and cold chain logistics service system of "fast food" is relatively complete. It has formed a complete system of cold chain logistics from the production base of cold chain logistics center, fresh food process distribution center to city distribution center.

Cold chain distribution business of catering-oriented enterprise must be equipped with preservation equipment required in distributing catering products. Develop frozen preservation technology of catering products logistics and establish catering products refrigerated chain, and develop cold chain logistics, then make products in low temperature state according to products' physiological need. This can form a cold chain: raw materials of catering products, semi-finished products, refrigerated car transport, catering freezers, kitchens. Only in this way can improve the efficiency of food product distribution, and ensure the quality of food products, and reduce the loss of beverage products.

It is well known that fast-food enterprises generally have special places for ingredients and fixed processing sites, most food of the stores are centrally distributed by the headquarters, such as yum group self-run cold-chain logistics serve for KFC, Pizza Hut. In addition, catering companies like Sea and Jiujiu Dock also use self-run cold-chain logistics. But currently some catering enterprises do not have professional cold chain logistics opera- 
tion system, neither special cold chain logistics distribution center. The construction of cold chain logistics distribution center is an engineering that needs huge investment and long recycling period, so these enterprises combine with social professional logistics enterprises to use third-party cold chain distribution, further achieve the development of cold chain logistics business. McDonald has been taken the way of cooperate with third-party logistics, and Havi is McDonald's global logistics service provider, and it has set up distribution centers in Beijing, Shanghai, and Guangzhou, which effectively ensure the rapid expansion of McDonald in China.

\subsection{Cold Chain House Distribution Service System}

Thanks to modern IT systems' support and distribution system gradual improvement, and people's pursuit of high levels of quality of life, consumers' shopping list transits from traditional commodities to vegetables, fruit and other fresh food and frozen food, ice cream, etc. E-commerce is the trend of social development, but whether the process can ensure the temperature and quality of food needs special attention, thus matching cold chain house distribution emerges, its development determined by market economic development.

Meanwhile, with the further expansion of the cold chain, from farm to fork "the whole cold chain" concept appears. In order to achieve "full cold chain", the key is to achieve seamless butt between consumer products and end-consumers. This mode of cold chain house distribution not only meets the needs of e-commerce distribution to ensure food quality and quality, but also makes the entire cold chain can be achieved, so that people's standard of living and quality of life get greater promotion. The market of online sales of frozen, fresh food once to be opened, demand of cold chain delivery service will rise sharply.

Delivery is B2C business that consumers order a certain amount and a certain variety of frozen and refrigerated food through electronic commerce, and deliver the goods at a specified time to specified places through the corresponding logistics technology provided by service provider. Cold chain house distribution grows very mature in Japan and Taiwan, and Beijing, Shanghai, as the two main leading cities in commercial development, have firstly done the experiment in this service area and attain effectiveness.

There are mainly three modes of service delivery of cold chain, one is B2C cold chain distribution business made by cold chain logistics enterprises using e-commerce platform, such as delivery business in the Beijing fast track foods company delivery business, fresh-food distribution business of Shunfeng in Beijing area. The second is cold chain logistics delivery business built by vertical e-commerce enterprises using self-run logistics, such as "fresh service" operated by Dianguo Net company (Beijing). The third is cold chain logistics delivery business built by green and organic food production base through self-run logistics or third-party logistics, such as Farm houses in Shanghai Dolly build cold chain through the Yamato black cat home delivery; Beijing Tuotuo commune, Shanghai Tiantian garden use the network platforms as Jingdong to operate fresh products and build self-run logistics for home delivery of the cold chain. The forth is cold chain logistics delivery business developed by C2C e-commerce through third-party network platforms and third-party logistics, such as vendors on network platforms of Taobao, Tianmao, first shop, Jingdong Mall use Shunfeng Suyun, urban 100 express for home delivery of the cold chain.

\subsection{Commodity Reserves Cold Chain Service System}

The mode of commodity reserves cold chain service system mainly is divided into following two species modes: one is national strategy reserves, and it is used to cope with emergency situation, and avoid price of health fresh food fluctuate sharply, such as Beijing Municipal Government construct reserves warehouse in city to store vegetables, pork and other products, and timely update cycle deployment, to ensure quality of health fresh food in reserves warehouse; in addition, reserve origin vegetables in area around Beijing to supple the supply of Beijing. The second is commercial reserves, in order to avoid market risk, mediation flows, tame prices, supply fruit and vegetable products listed by cold storage, and then arrange the time to market, implement delays or cross-quarter sales.

\section{The Development Trend of City-Oriented Cold Chain Logistics Service System for Fresh Agricultural Products}

Urban agricultural self-sufficiency rate is low, and most varieties rely on outside supply. To meet the needs of city residents for fresh produce, fresh agricultural products circulation expand from regional to region, and took 
on trend of cross-regional, trans-national circulation, global circulation. Urban development needs large scale of fresh agricultural products supply, supported by more competitive and advanced cold chain logistics system. The development goal of fresh agricultural products cold chain logistics system adapted city's development is summed up in the following:

\subsection{The Management System: Government-Led and Multi-Subjects}

City-oriented fresh agricultural products cold chain logistics service system has significant social attribute, it should make full use of the Government's macro-control. The development planning of cold chain logistics of agricultural products suitable for city needs not only intensive Logistics Center, but also convenient Community stores. According to the fresh agricultural products' supply and demand characteristic of the city, it is necessary to design policies to encourage agricultural development of cold chain logistics to make agricultural products access to town, ensure city basic supply of agricultural products, strengthen the supervision system, ensure product quality and safety of the fresh products into town by the cold chain. Build linkage mechanism of governments, industry associations and business, stress the Government's macro-control, and also pay attention to the industry guidance and enterprises' discipline, form a distinct stereo system of multi- subjects and distinct layer level.

\subsection{The Service Network: Multi-Tier Collaboration, Multi-Investment}

Logistics services are based on the network service system, and city’s cold chain logistics service system is full cold chain logistics system made up by the city Mons supply network system and distribution network in urban areas. Urban fresh agricultural products cold chain logistics system is adapted to the development of logistics' systematic and socialization, organized by the cold chain logistics network, cold chain facilities network and information network. City-oriented cold chain logistics should develop the relationship of parallel, disjoint to coordinated relationship through the integration of resources required by urban traffic environment, and provide customers with an integrated service network system. Through mutual coordination and integration to create the most appropriate cold chain logistics network, and through network management of cold chain operations, resource and information in the Logistics Management Office, to achieve rapid response and cost optimization of cold chain logistics under the constraints of urban transportation.

City cold chain logistics developments require increased investment, and establish diversified investment mechanism of “Government guidance, business operations, multi-participators”. Whether it's logistics companies, wholesale, and distribution centers, the Government's investment of support and guide in the initial stage is essential. Today's cold chain logistics of agricultural products in the city is mostly still in its initial stages of development, on the one hand, lack of experience in aspects of hardware infrastructure, micro-technology and macro-management; on the other hand, since the length of "field of a table" the whole logistics process chain is too long, and one enterprise is difficult to complete cold chain logistics system construction. Therefore, according to the development of cold chain logistics characteristics in the city and present actual needs of development, Governments need to increase capital investment, and gradually formed a diversified input mechanism of multiparty.

\subsection{Distribution Mode: Common, Diversification}

Intensive distribution is the inevitable trend of development because of urban road and warehouse land and environmental pressures. The nature of common distribution is enterprises in order to achieve resources share. Based on the trust and benefit of cooperation, enterprises share resources in the way of strategy union, collaborative combination and common of logistics through integration, and distribute after combination of different commodity, then improve logistics service level, reduce distribution cost, improve profit capacity, feedback information quickly, upgrade efficient circulation of distribution of overall social commodity, further promote commercial environment and effective use of social resources. Common distribution's mode is flexible and diversified, it includes not only several enterprises jointly distribute, but also invest in the construction of logistics and distribution facilities, and a third-party logistics company providing services for multiple customers.

According to the urban characteristics of the cold chain logistics of agricultural products, we know it is necessary to build cold chain logistics system formed by a variety of organizations. First of all, regard the city dis- 
tribution center as the core to develop urban common distribution cold chain system. Secondly, develop integrated cold chain logistics system of agricultural products' supply and marketing that regarding the leading enterprise as the core, and multi-level traditional channel of cold chain logistics that based on the wholesale market, and pay more attention to consumers-oriented cold chain house distribution regarding e-commerce platform as the core. Build development system of cold chain logistics mode of multiple models coexist and different model system for resources, promote the healthy, stable and rapid development of city's cold chain logistics of agricultural products.

\subsection{Service Process: Professional, Standardized, Visualized}

From the point of view of economics, specialization helps to reduce the long-term average cost. In cold chain management, therefore, we need to abandon the operating modes of "large and all-inclusive" or "small and all-inclusive", and the way of specialized, intensive, and large-scale. The increasing improvement of deepening of each subject's division and specialization makes the previous ability of coordination and cohesion to be the key to improve the efficiency of food cold chain logistics service. The standardization of cold chain logistics determines operation efficiency of the whole service system. Standardization is involved in the whole process of cold chain logistics, including pre-cold, cold sorting and processing, standardization of refrigerated transport and refrigerated storage link, involving not only technical standardization but also standardization of tools and temperature control method. Using cold chain logistics in the whole process, and orbit standardization into full-scope, which can reach optimal quality of the cold chain logistics services. City cold chain logistics' processes should be combined with cold chain logistics of agricultural products' international standards guidelines and standards, and strengthen the operation specification.

Cold chain logistics combine with computer network and information technology to closely link separate business flow, logistics and procurement, transport, warehousing, distribution and other aspects, forming a cold-chain logistics information network, to achieve full visualization. Information platform integrates farmers, manufacturers, suppliers, wholesalers, end retailers as well as consumers together to form a complete set of supply chain to achieve effective control of food cold chain logistics process, in particular the temperature control and quality control. Through establishing a highly developed cold-chain logistics information network to achieve full sharing of information, visibility of entire process of cold chain, in order to reduce the cost of food cold chain logistics, improve the service quality of the cold chain and improve the customers' experience.

\subsection{Cold Chain's Equipment and Technology: Information, Intelligence, Green}

The cold chain logistics of fresh agricultural products includes transportation, distribution processing, warehousing, distribution, and other links, and each link is facing technical guarantee and management optimization problems. "Freshness" is the soul and value of the cold chain logistics. It is a process of maintaining quality and freshness of food from picking to transport to market, and put forward higher requirements to food cold chain logistics' efficiency and preservation techniques in circulation. It also needs to rely on advanced cold chain techniques to enhance the value of the food supply chain as a whole, and create value for professional cold chain logistics business and guarantee efficient operation in each link. Cold chain technologies are interrelated and interdependent. They form a unique whole technical network based on food cold chain logistics, thus ensure the agricultural preserve and increase the value of each node in the transfer process.

Through the original innovation, integrated innovation and the introduction of secondary innovation and other forms, and constantly raise the level of cold chain logistics' infrastructure of the city, strengthen the production, storage, processing, transport, marketing technology and the transformation and upgrading of each node to promote urban agricultural leap-forward development of cold chain logistics in China. One is continuing to strengthen transport trunk line and infrastructure transformation in subsidiary field station, form integrated transport network and perfect warehouse distribution facilities suitable to multimodal transportation; the second is encouraging application of GPS, automatically recognition, and other technologies, link up carriers, users, manufacturers, suppliers and other related units through network platform and information technology to achieve full monitoring, resources shared and information shared on agricultural, which can improve social overall transport efficiency; the third is introducing and promoting automation and warehouse management systems, cold storage technology of vacuum precooling technology, non-destructive testing and treatment technology, transport temperature control technology and other advanced technologies to improve the ability of technical innovation and 
technical updates.

\section{Acknowledgements}

The fund project, the National Social Science Fund "The research of fresh agricultural products cold chain logistics management system for the needs of the city” (11BJY111).

\section{References}

[1] Reddy, C.M., Malliyala, S., Naresh, Y., Raghunandan, H.V. and Jinadatharaya, H. (2012) Good Cold Chain Management Practices. Journal of Pharmacy Research, 10, 5043-5047.

[2] Wang, X.Y. and Wu, F.Y. (2012) Get Distribution Back into Public-Visit to the Academy of Li Yanlin, Director of Research Center of Modern Logistics. Transportation Manager World, No. 7, 29-32.

[3] Yu, K.Y. (2011) The Analysis of Urban Distribution-Oriented Mechanism. Business Studies, No. 3, 177-180.

[4] Zhang, X.Z. and Chen, G.Y. (2009) The Selection of Agricultural Product Supply Chain's Operation Mode in China. China Circulation Economy, 23, 57-60. 